Acta Crystallographica Section F

Structural Biology

and Crystallization

Communications

ISSN 1744-3091

\section{Two crystal forms of a helix-rich fatty acid- and retinol-binding protein, Na-FAR-1, from the parasitic nematode Necator americanus}

\section{Mads Gabrielsen, ${ }^{\mathrm{a} *} \mathrm{M}$. Florencia Rey-Burusco, ${ }^{b}$ Kate Griffiths, ${ }^{c}$ Andrew J. Roe, ${ }^{a}$ Alan Cooper, Brian O. Smith, ${ }^{\text {e Malcolm W. }}$ Kennedy $^{\mathrm{c}, \mathrm{e} *}$ and Betina Corsico ${ }^{\mathrm{b}}$}

a Institute of Infection, Immunity and Inflammation, University of Glasgow, Glasgow, Scotland, ' Instituto de Investifaciones Bioquimicas de La Plata, CONICET-UNLP, Facultad de Ciencias Medicas, Universidad Nacional de La Plata, La Plata, Argentina, 'Insitute of Biodiversity, Animal Health and Comparative Medicine, University of Glasgow, Glasgow, Scotland, 's School of Chemistry, University of Glasgow, Glasgow, Scotland, and e Institute of Molecular, Cell and Systems Biology, University of Glasgow, Scotland

Correspondence e-mail: mgabr@chem.gla.ac.uk, malcolm.kennedy@glasgow.ac.uk

Received 4 May 2012

Accepted 23 May 2012

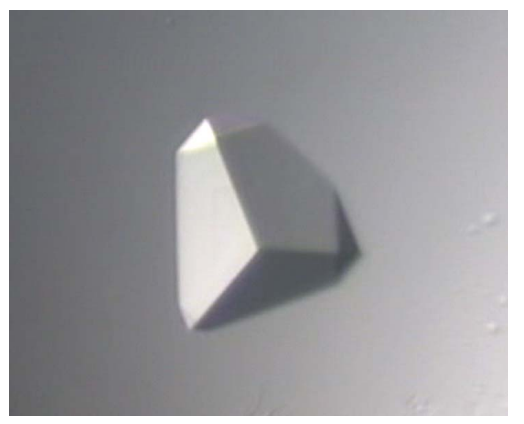

Na-FAR-1 is an unusual $\alpha$-helix-rich fatty acid- and retinol-binding protein from Necator americanus, a blood-feeding intestinal parasitic nematode of humans. It belongs to the FAR protein family, which is unique to nematodes; no structural information is available to date for FAR proteins from parasites. Crystals were obtained with two different morphologies that corresponded to different space groups. Crystal form 1 exhibited space group $P 432$ (unit-cell parameters $\left.a=b=c=120.80 \AA, \alpha=\beta=\gamma=90^{\circ}\right)$ and diffracted to $2.5 \AA$ resolution, whereas crystal form 2 exhibited space group $F 23$ (unit-cell parameters $a=b=c=240.38 \AA$, $\alpha=\beta=\gamma=90^{\circ}$ ) and diffracted to $3.2 \AA$ resolution. Crystal form 2 showed signs of significant twinning.

\section{Introduction}

Fatty acid- and retinol-binding (FAR) proteins are a structurally novel class of $\sim 20 \mathrm{kDa}$ lipid-binding proteins that are only found in nematodes. They belong to a family of proteins that exist in around seven different isoforms in each species and which are differentially produced at different life-cycle and developmental stages (Kennedy et al., 1997; Garofalo, Kennedy et al., 2003). They are hypothesized to play roles in host-parasite interaction and pathogenesis through the sequestration or delivery of pharmacologically or immunologically active small lipids, although there is still much to learn about their biological functions. Pertinent to this, FAR proteins have been found to be prominent components of the secretions of nematode parasites of humans, other animals and plants (Kennedy et al., 1997; Suire et al., 2001; Basavaraju et al., 2003). Their structures are predicted to be rich in $\alpha$-helices and they have no structural counterparts in other animal groups (Kennedy et al., 1997; Basavaraju et al., 2003). The crystal structure of one FAR protein, Ce-FAR-7, from the free-living nematode Caenorhabditis elegans has recently been reported (Jordanova et al., 2009). However, according to sequence comparison this protein belongs to a separate group within the FAR protein family that differs from those secreted by parasitic nematodes into host tissues (Garofalo, Rowlinson et al., 2003). FAR proteins, which are already used as diagnostic tools (Burbelo et al., 2009), are attractive potential targets for drug or vaccine development to generate new antihelminthic controls.

Necator americanus is a blood-feeding nematode hookworm which causes anaemia and growth stunting, infecting 750 million people in tropical and subtropical areas with poor hygiene and economic conditions (Hotez et al., 2004). Among the genes transcribed at high levels by $N$. americanus, one that encodes a FAR protein, Na-FAR-1, has been identified (Daub et al., 2000).

Here, we report the bacterial expression of recombinant $\mathrm{Na}-$ FAR-1, its purification and its crystallization in two different space groups: $P 432$ and $F 23$.

\section{Materials and methods}

\subsection{Protein expression and purification}

The Na-FAR-1 coding sequence was obtained from the Nematode Transcriptome Database (NEMBASE4; sequence ID NAC00128) and an encoding cDNA was chemically synthesized (GeneArt AG, 


\section{crystallization communications}

Regensburg, Germany) with a polyhistidine-sequence affinity tag added at the N-terminus and cloned into pET11a expression vector. The plasmid was sequence-verified and transformed into Escherichia coli BL21 (DE3) cells. The bacteria were grown in LB medium at $310 \mathrm{~K}$; protein production was induced with $1.0 \mathrm{~m} M$ IPTG and cells were harvested after $4 \mathrm{~h}$. The cells were resuspended in $40 \mathrm{ml}$ binding buffer (20 $\mathrm{m} M$ Tris- $\mathrm{HCl}$ pH 7.8, $500 \mathrm{~m} M \mathrm{NaCl}, 5 \mathrm{~m} M$ imidazole) and lysed by sonication. The lysate was cleared by centrifugation. The supernatant was applied onto a nickel-affinity column (Novagen, Darmstadt, Germany) and washed in ten column volumes (CV) of binding buffer, followed by $6 \mathrm{CV}$ wash buffer $(20 \mathrm{mM}$ Tris- $\mathrm{HCl} \mathrm{pH}$ $7.8,500 \mathrm{mM} \mathrm{NaCl}, 20 \mathrm{~m} M$ imidazole). The protein was eluted with $20 \mathrm{~m} M$ Tris- $\mathrm{HCl} \mathrm{pH}$ 7.5, $500 \mathrm{~m} M \mathrm{NaCl}, 250 \mathrm{~m} M$ imidazole over $6 \mathrm{CV}$.

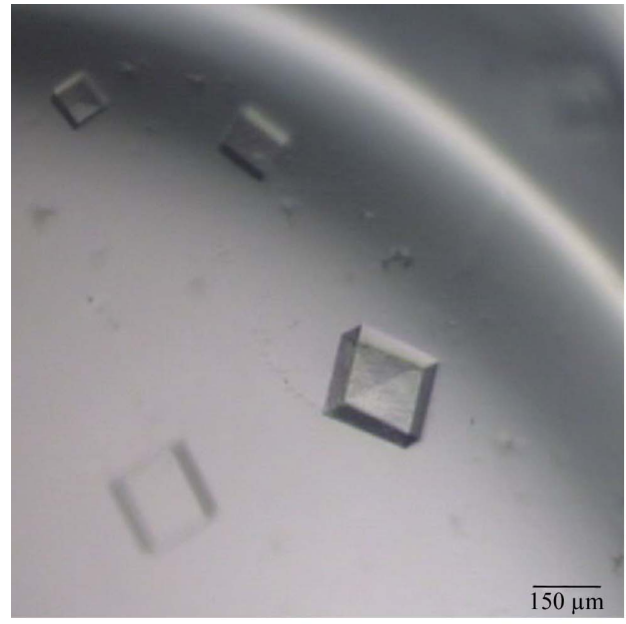

(a)
A second purification step was performed using size-exclusion chromatography (Superdex 75 HR 10/300; GE Healthcare, Little Chalfont, England). The final protein buffer was $20 \mathrm{mM}$ Tris- $\mathrm{HCl} \mathrm{pH}$ 7.5. The typical protein yield was around $30 \mathrm{mg}$ of protein per litre of culture. The molecular mass of this recombinant Na-FAR-1 was calculated to be $18776.4 \mathrm{Da}$, including the affinity tag, and comprised 170 residues in total.

\subsection{Crystallization}

The protein was concentrated to approximately $5 \mathrm{mg} \mathrm{ml}^{-1}$ and initial crystallization attempts were performed in 96-well sitting-drop plates using vapour diffusion and three commercially available

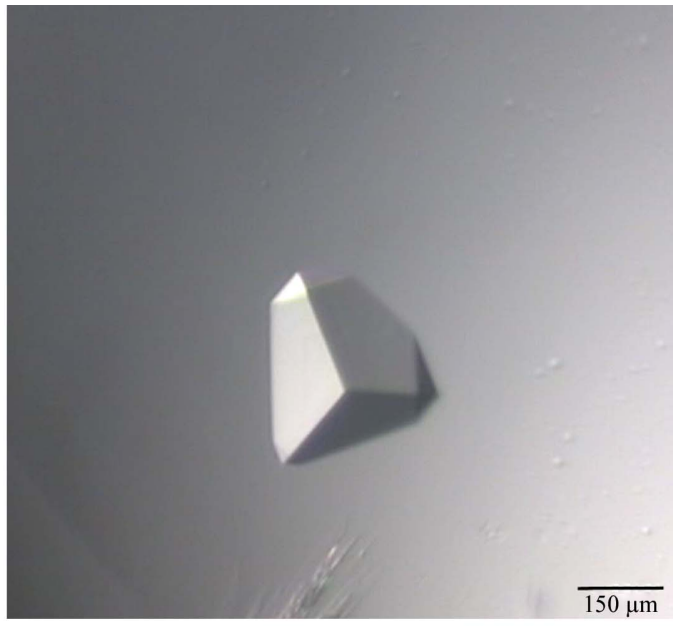

(b)

Figure 1

Crystals of Na-FAR-1 from $N$. americanus. The recombinant protein was purified from E. coli and optimized crystals were grown in $38 \%$ PEG $300,100 \mathrm{~m} M$ phosphatecitrate $\mathrm{pH}$ 4.2. (a) Crystal form 1, space group $P 432(a=120.8 \AA)$; $(b)$ crystal form 2, space group $F 23(a=240.4 \AA)$.

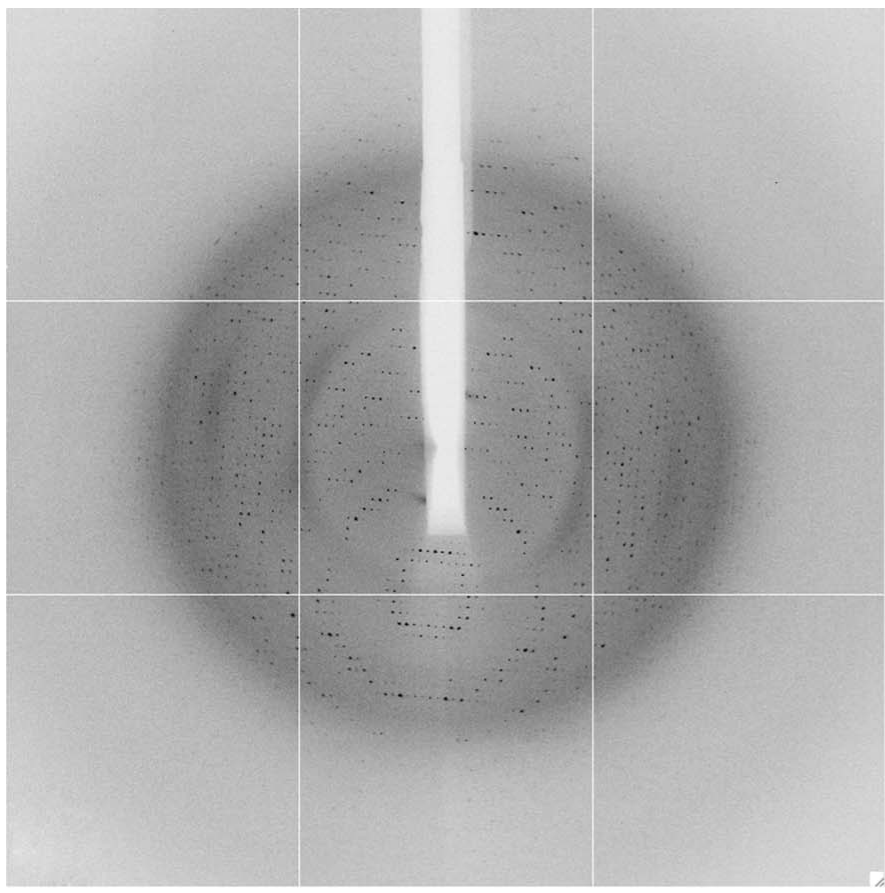

(a)

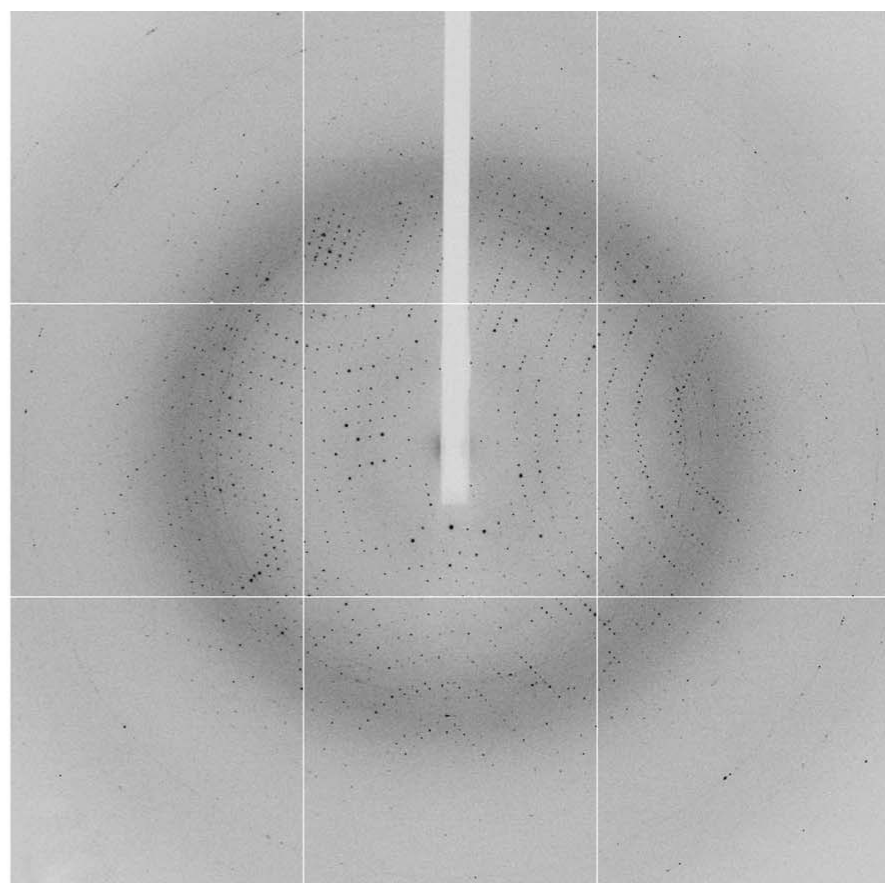

(b)

Figure 2

Sample diffraction patterns of crystal forms $1(a)$ and $2(b)$. Diffraction extended to beyond 2 A resolution for form 1 and to beyond $2.5 \AA$ resolution for form 2 . 
Table 1

Data-collection and reduction statistics.

Values in parentheses are for the highest resolution shell. Diffraction was observed beyond the resolutions presented here, but the data were scaled to $2.50 \AA$ for crystal form 1 and $3.20 \AA$ for crystal form 2 based on the $R_{\text {meas }}$ and $R_{\text {p.i.m. }}$ values. If the data were scaled further there was a dramatic increase in $R_{\text {meas }}$ in particular. Crystal form 1 scaled to $2.1 \AA$ resolution still showed $100 \%$ completeness and an $\langle I / \sigma(I)\rangle$ of 2.5 in the highest resolution shell (2.21-2.10 $\AA$ ). However, the $R_{\text {meas }}$ changed to $17.8 \%$ overall and $196.7 \%$ in the highest resolution shell. Crystal form 2 showed similar behaviour, although the data could only be scaled to $2.9 \AA$ resolution with $100 \%$ completeness and an $\langle I / \sigma(I)\rangle$ of 3.0 in the highest resolution shell (3.06-2.90 $\AA$ ), with an $R_{\text {meas }}$ of $23.5 \%$ overall and $118 \%$ in the highest resolution shell.

\begin{tabular}{lll}
\hline & Crystal form 1 & Crystal form 2 \\
\hline Space group & $P 432$ & $F 23$ \\
Unit-cell parameters $\left(\AA{ }^{\circ}\right)$ & $a=b=c=120.80$, & $a=b=c=240.38$, \\
& $\alpha=\beta=\gamma=90.0$ & \multicolumn{1}{c}{$\alpha=\beta=\gamma=90.0$} \\
Resolution $(\AA)$ & $49.32-2.50(2.64-2.50)$ & $69.39-3.20(3.37-3.20)$ \\
Observed reflections & 302052 & 404552 \\
Unique reflections & 10986 & 19069 \\
Multiplicity & $27.5(28.5)$ & $21.2(20.9)$ \\
Completeness $(\%)$ & $100.0(100.0)$ & $100.0(100.0)$ \\
$R_{\text {meas }}(\%)$ & $10.6(59.7)$ & $18.8(53.0)$ \\
$R_{\text {p.i.m. }}(\%)$ & $2.0(11.1)$ & $4.1(11.6)$ \\
$\langle I / \sigma(I)\rangle$ & $33.3(7.6)$ & $18.3(6.9)$ \\
Wilson $B\left(\AA^{2}\right)$ & 46.95 & 66.55 \\
\hline
\end{tabular}

crystallization screens. The protein solution was mixed with reservoir solution in a 1:1 ratio to give a final volume of $1 \mu \mathrm{l}$ using a Cartesian Honeybee 81 (Genomic Solutions, Huntingdon, England) and the trays were stored at $293 \mathrm{~K}$. Small crystals (approximately $20 \times 20 \times$ $20 \mu \mathrm{m}$ ) were observed in Cryo Screen II (Emerald BioSystems, USA) condition No. 18 [40\% polyethylene glycol (PEG) 300, $100 \mathrm{mM}$ phosphate-citrate $\mathrm{pH}$ 4.2]. Larger optimized crystals were grown in 24-well sitting-drop trays (Hampton Research) using drops set up with a 1:1 ratio of protein solution and optimized reservoir solution (38\% PEG 300, $100 \mathrm{~m} M$ phosphate-citrate $\mathrm{pH} 4.2$ ) to give a final drop volume of $3 \mu \mathrm{l}$. Crystals appeared within $10 \mathrm{~d}$. The crystals were plunged directly into a stream of cooled gaseous nitrogen $(100 \mathrm{~K}$; Oxford Cryosystems, Oxford, England) without any further cryoprotection.

\subsection{Data collection and processing}

Data were collected from initial crystals at station I02 of Diamond Light Source (DLS; Didcot, Oxfordshire, England). Low-resolution diffraction data were observed to beyond $7 \AA$. Data were collected from optimized crystals at stations I03 and I04 of DLS and were collected over $180^{\circ}$ with $1^{\circ}$ oscillation at wavelengths of 0.9763 and $0.9796 \AA$, respectively. Data were processed with MOSFLM (Leslie $\&$ Powell, 2007) and were scaled in SCALA (Evans, 2006). The space

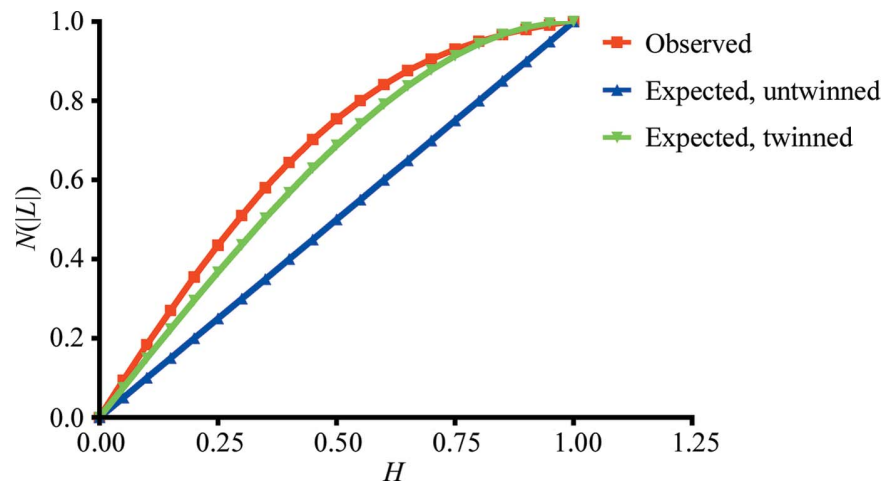

Figure 3

Output from CTRUNCATE for the $L$-test for twinning for crystal form 2. The observed values fitted closely to the values expected for perfect twinning.
Table 2

The nature of the asymmetric unit has yet to be determined, but is expected to contain one or two subunits in the case of crystal form 1 and five or six subunits in the case of crystal form 2 .

\begin{tabular}{|c|c|c|c|c|c|}
\hline \multicolumn{3}{|c|}{ Crystal form $1(P 432)$} & \multicolumn{3}{|c|}{ Crystal form 2 (F23) } \\
\hline $\begin{array}{l}\text { Matthews } \\
\text { coefficient } \\
\left(\AA^{3} \mathrm{Da}^{-1}\right)\end{array}$ & $\begin{array}{l}\text { Solvent } \\
\text { content } \\
(\%)\end{array}$ & $\begin{array}{l}\text { Monomers } \\
\text { in asymmetric } \\
\text { unit }\end{array}$ & $\begin{array}{l}\text { Matthews } \\
\text { coefficient } \\
\left(\AA^{3} \mathrm{Da}^{-1}\right)\end{array}$ & $\begin{array}{l}\text { Solvent } \\
\text { content } \\
(\%)\end{array}$ & $\begin{array}{l}\text { Monomers } \\
\text { in asymmetric } \\
\text { unit }\end{array}$ \\
\hline 3.91 & 68.60 & 1 & 3.86 & 68.13 & 4 \\
\hline 1.96 & 37.19 & 2 & 3.09 & 60.16 & 5 \\
\hline \multirow{3}{*}{1.30} & 5.79 & 3 & 2.57 & 52.19 & 6 \\
\hline & & & 2.20 & 44.22 & 7 \\
\hline & & & 1.93 & 36.26 & 8 \\
\hline
\end{tabular}

groups were confirmed by POINTLESS (Evans, 2006). Twinning analysis was performed by analysing the output from CTRUNCATE (part of $S C A L A$ ). All of these programs are part of the CCP4 suite of programs (Winn et al., 2011).

\section{Results}

The crystals grew in two different morphologies with approximate dimensions of $200 \times 200 \times 100 \mu \mathrm{m}$ (Fig. 1) in the same condition and in the same crystal tray well. Crystal form 1 (Fig. 1a) belonged to space group $P 432$ (unit-cell parameters $a=b=c=120.804 \AA$ ), with Bragg diffraction observed to beyond $2 \AA$ resolution (Fig. $2 a$ ). The data were cut back to $2.5 \AA$ resolution based on an $R_{\text {meas }}$ of $59.7 \%$ and an $R_{\text {p.i.m. }}$ of $11.1 \%$ in the highest resolution shell (see Table 1 for complete details).

Crystal form 2 (Fig. 1b) was initially processed and scaled in space group $F 432$ (unit-cell parameters $a=b=c=241.61 \AA$ ). However, inspection of the cumulative distribution of $L$ (Fig. 3) and the moments of $E$ (1.4 for the fourth moment; the expected values are 2 for an untwinned crystal and 1.5 for a perfect twin) suggested that the crystal was near-perfectly twinned and the actual space group was determined to be $F 23$. The data were scaled to $3.2 \AA$ resolution (Fig. $2 b$ ) based on an $R_{\text {meas }}$ of $53.0 \%$ and an $R_{\text {p.i.m. }}$ of $11.6 \%$ in the highest resolution shell (see Table 1 for full details).

Both crystal forms diffracted further, but the data were scaled to conservative estimates based on the $R_{\text {meas }}$ and $R_{\text {p.i.m. values. Both }}$ data sets were anisotropic, with sectors of the crystals exhibiting poorer diffraction to a lower resolution, and these may give rise to the rapid increase in the $R_{\text {meas }}$ and $R_{\text {p.i.m. }}$ values when the highest resolution limit is extended.

The nature of the asymmetric unit is unclear for both crystal forms, with crystal form 1 assumed to contain one or two subunits and crystal form 2 between four and eight subunits (see Table 2 for details). The corresponding Matthews coefficients range from 3.91 to $1.96 \AA^{3} \mathrm{Da}^{-1}$ for crystal form 1 and from 3.86 to $1.93 \AA^{3} \mathrm{Da}^{-1}$ for crystal form 2 .

\section{Conclusions}

We have crystallized the fatty acid- and retinol-binding protein NaFAR-1 from the parasitic nematode $N$. americanus in two crystal forms, one of which showed signs of significant twinning. The data set from crystal form 1 was scaled to $2.5 \AA$ resolution, whereas the data set from crystal form 2 was scaled to $3.2 \AA$ resolution. As there are no known structures with sufficiently high sequence similarity in the Protein Data Bank (Velankar et al., 2012) to attempt molecular replacement, work is now under way to obtain experimental phases. 


\section{crystallization communications}

We are grateful to the Diamond Light Source (Proposal No. mx1229) for access to beamline stations I03 and I04. This work was supported by Wellcome Trust grant No. 083625 to MWK, AC, BOS and BC, the National Research Council of Argentina (CONICET) and a Biotechnology and Biological Sciences Research Council grant to MG and AJR (BB/G011389/1).

\section{References}

Basavaraju, S. V., Basavaraju, S., Zhan, B., Kennedy, M. W., Liu, Y., Hawdon, J. \& Hotez, P. J. (2003). Mol. Biochem. Parasitol. 126, 63-71.

Burbelo, P. D., Leahy, H. P., Iadarola, M. J. \& Nutman, T. B. (2009). PLoS Negl. Trop. Dis. 3, e438.

Daub, J., Loukas, A., Pritchard, D. I. \& Blaxter, M. (2000). Parasitology, 120, 171-184.

Evans, P. (2006). Acta Cryst. D62, 72-82.

Garofalo, A., Kennedy, M. W. \& Bradley, J. E. (2003). Med. Microbiol.
Immunol. 192, 47-52.

Garofalo, A., Rowlinson, M.-C., Amambua, N. A., Hughes, J. M., Kelly, S. M., Price, N. C., Cooper, A., Watson, D. G., Kennedy, M. W. \& Bradley, J. E. (2003). J. Biol. Chem. 278, 8065-8074.

Hotez, P. J., Brooker, S., Bethony, J. M., Bottazzi, M. E., Loukas, A. \& Xiao, S. (2004). N. Engl. J. Med. 351, 799-807.

Jordanova, R., Groves, M. R., Kostova, E., Woltersdorf, C., Liebau, E. \& Tucker, P. A. (2009). J. Biol. Chem. 284, 35818-35826.

Kennedy, M. W., Garside, L. H., Goodrick, L. E., McDermott, L., Brass, A., Price, N. C., Kelly, S. M., Cooper, A. \& Bradley, J. E. (1997). J. Biol. Chem. 272, 29442-29448.

Leslie, A. G. W. \& Powell, H. R. (2007). Evolving Methods for Macromolecular Crystallography, edited by R. J. Read \& J. L. Sussman, pp. 41-51. Dordrecht: Springer.

Suire, S., Stewart, F., Beauchamp, J. \& Kennedy, M. W. (2001). Biochem. J. 356, 369-376.

Velankar, S. et al. (2012). Nucleic Acids Res. 40, D445-D452.

Winn, M. D. et al. (2011). Acta Cryst. D67, 235-242. 